\title{
Analisis Hubung Singkat Pada Jaringan Tegangan Menengah 20 kV Penyulang Kedonganan
}

\author{
I Gde Komang Jaryanta Arya Mantara ${ }^{1}$, I. A. Dwi Giriantari ${ }^{2}$, I Wayan Sukerayasa ${ }^{3}$
}

\begin{abstract}
In this study, the short circuit simulation conducted of 3-phase, phase to phase and single line to ground fault in several alternate site points which are selected based on the interruption that might occur in the feeders and from the GI base point thought end point in Kedonganan feeders. The value of short circuit current are used to set the time setting of over current relay to make the protection equipment run according to safety requirements. Based on the analysis result, it shows that the current interruptions are influenced by the distant of interruption, the more distant the point then the smaller short circuit current would happened, and vice versa. The increasing short circuit current can caused a grading time in relay in each alternate location with average grading time about 0,4 second. Rearrangement of protection system in short circuit is recommended especially in protection system based on outcome which can improve the sensitivity and selectivity for better protection system.
\end{abstract}

Intisari- Pada penelitian ini dilakukan simulasi gangguan hubung singkat 3-fasa, fasa ke fasa dan gangguan hubung singkat 1 fasa ke tanah yang ditentukan dititik lokasi gangguan alternatif yang dipilih sesuai dengan gangguan yang terjadi pada penyulang dari pangkal GI sampai ujung penyulang Kedonganan. Nilai arus gangguan hubung singkat tersebut digunakan untuk menentukan setting waktu kerja relay arus lebih agar peralatan proteksi dapat bekerja sesuai dengan persyaratan pengaman. Berdasarkan hasil analisis, menunjukkan bahwa arus gangguan tersebut dipengaruhi oleh jarak titik gangguan, semakin jauh jarak titik gangguan dari power grid maka semakin kecil arus gangguan hubung singkatnya begitu juga sebaliknya. Peningkatan arus ganguan hubung singkat mengakibatkan selisih waktu kerja relay di tiap lokasi alternatif dengan selisih waktu range 0,4 detik. Direkomendasikan untuk dilakukannya setting ulang pada sistem proteksi sesuai dengan hasil perhitungan yang dapat memperbaiki selektifitas dan sensitifitas sehingga didapatkan sistem proteksi yang baik.

Kata Kunci- Gangguan hubung singkat, sistem proteksi, relay arus lebih

${ }^{1}$ Mahasiswa, Program Studi Teknik Elektro dan Komputer Fakultas Teknik Universitas Udayana Jln. Kampus Bukit Jimbaran 80361 INDONESIA (tlp: 0361-703315; fax: 0361-4321; komangjaryanta@gmail.com )

2, 3 Dosen, Program Studi Teknik Elektro dan Komputer Fakultas Teknik Universitas Udayana, Jln. Jalan Kampus Bukit Jimbaran 80361 INDONESIA (telp: 0361-703315; fax: 03614321;e-mail: dayu.giriantari@unud..ac.id sukerayasa@unud.ac.id

\section{Pendahuluan}

Penyulang Kedonganan adalah salah satu penyulang yang bersumber dari gardu induk (GI) Nusa Dua. Seperti pada umumnya, penyulang Kedonganan memiliki fungsi untuk menyalurkan suplay tenaga listrik menuju konsumen di daerah Kedonganan dan sekitarnya terutama pada kampus Universitas Udayana. Dari perencanaan rekonfigurasi untuk meningkatkan keandalan dan kontinyuitas pelayanan di kampus Universitas Udayana, maka dilakukan rekonfigurasi jaringan tegangan menengah. Disamping itu juga kampus Universitas Udayana menyediakan suplay cadangan berupa generator set sebagai backup suplay jika ada pemadaman dari PLN. Sistem backup dengan menggunakan generator set saat ini masih di desain secara partial sehingga tidak menjamin keandalannya [1].

Maka dari itu analisa gangguan hubung singkat diperlukan untuk mempelajari sistem tenaga listrik baik waktu perencanaan maupun setelah beroperasi sistem tersebut. Untuk mencegah meluasnya gangguan yang terjadi pada penyulang Kedonganan. Analisa hubung singkat ini digunakan untuk menentukan setting relay proteksi untuk melindungi system tersebut dari kemungkinan adanya gangguan dari faktor external dan internal, agar memperoleh sistem kelistrikan yang lebih handal diharapkan bisa meningkatkan pelayanan kelistrikan di area kampus Universitas Udayana Bukit Jimbaran.

Studi dilakukan dengan cara mengumpulkan data-data seperti : mencari single line diagram penyulang Kedonganan, data transformator, beban transformator, panjang penghantar dan jenis penghantar, data gangguan yang terjadi pada penyulang Kedonganan, data relay penyulang Kedonganan. Penelitian ini dibantu dengan software.

\section{Gangguan Hubung SingKat}

Gangguan hubung singkat adalah gangguan yang terjadi karena adanya kesalahan antara bagian-bagian yang bertegangan diakibatkan dari timbulnya arus yang jauh lebih besar dari pada arus normal [2]. Gangguan hubung singkat pada sistem distribusi primer dapat juga disebabkan berdasarkan penyebab external dan penyebab internal [2]. Salah satu upaya yang dilakukan untuk mengatasi gangguan tersebut dilakukan analisis hubung singkat sebagai tahap awal untuk menanggulangi sehingga sistem proteksi yang tepat pada sistem tenaga listrik dapat ditentukan. Perhitungan arus hubung singkat dapat dihitung dengan menggunakan persamaan-persamaan berikut :

Arus gangguan dapat dihitung dengan menggunakan persamaan umum [3] :

$$
I=\frac{V}{Z}
$$

Keterangan :

$\mathrm{I}=$ Arus hubung singkat (Amp) 
$\mathrm{V}=$ Tegangan Sumber (volt)

$\mathrm{Z}=$ Impedansi jaringan (ohm)

\section{A. Impedansi Sumber}

Sebelum menghitung impedansi sumber pada sisi $20 \mathrm{kV}$ harus diketahui nilai kapasitas daya hubung singkat (MVA). Kapasitas daya hubung singkat dapat dihitung sebagai berikut [3] :

$$
M V A_{h s}=I_{h s} 3 \emptyset \max \times\left(V_{\text {primer trafo }} \times \sqrt{3}\right)
$$

Keterangan :

$$
\mathrm{MVA}_{\mathrm{hs}} \quad=\text { Kapasitas daya hubung singkat GI (MVA) }
$$

$\mathrm{I}_{\mathrm{hs}} 3 \emptyset \mathrm{max}=$ Arus hubung singkat 3 fasa maks GI $(\mathrm{kA})$

$\mathrm{V}_{\text {prime trafo }} \quad=$ Tegangan Primer trafo $(\mathrm{kV})$

Untuk menghitung impedansi sumber di sisi $20 \mathrm{kV}$, maka dihitung dulu impedansi sumber disisi $150 \mathrm{kV}$, dengan rumus :

$$
Z_{(\text {sisi } 150 \mathrm{kV})}=\frac{k V^{2}}{M V A_{h s}}
$$

Keterangan :

$\mathrm{Z}_{(\text {sisi } 150 \mathrm{kV})} \quad=$ Impedansi sumber $(\Omega)$

$\mathrm{kV}^{2} \quad=$ Tegangan sisi primer trafo tenaga $(\mathrm{kV})$

$\mathrm{MVA}_{\mathrm{hs}} \quad=$ Kapasitas daya hubung singkat GI (MVA)

Arus hubung singkat di sisi $20 \mathrm{kV}$ diperoleh dengan mengkorversi impedansi sumber di sisi $150 \mathrm{kV}$ ke sisi $20 \mathrm{kV}$, dengan rumus :

$$
Z_{(\text {sisi } 20 \mathrm{kV})}=\frac{k V_{(\text {sisi sekunder trafo })^{2}}}{k V_{(\text {tegangan primer trafo })}{ }^{2}} \times Z_{(\text {sisi } 150 \mathrm{kV})}
$$

\section{B. Impedansi Transformator}

Untuk mencari nilai Impedansi trafo $(\mathrm{Zt})$ dihitung dengan cara sebagai berikut. Langkah pertama mencari $\mathrm{Zt}$ pada $100 \%$ dengan rumus [4] :

$$
Z_{t}=\frac{k V^{2} \text { sisi sekunder }}{M V A_{\text {trafo }}}
$$

Keterangan :

$$
\mathrm{Zt} \quad=\text { Impedansi } \operatorname{Trafo}(\Omega)
$$

$\mathrm{kV} 2$ sisi sekunder $=$ Tegangan sisi sekunder trafo $(\mathrm{kV})$

MVAtrafo = Kapasitas daya trafo (MVA)

Tahap selanjutnya mencari impedansi trafo tenaga:

1. Impedansi urutan positif negatif $(\mathrm{Zt} 1=\mathrm{Zt} 2)$ dihitung dengan rumus :

$Z_{t}=\% Z_{t}$ yang diketahui $\times Z_{t}($ pada $100 \%)$

2. Impedansi urutan nol ( $\mathrm{Zt} 0)$

Sebelum menghitung $\mathrm{Zt0}$ terlebih dahulu harus mengetahui data trafo yang digunakan seperti dari kapasitas belitan delta yang ada dalam trafo. Dalam perhitungan digunakan persamaan

$X_{t 0}=10 \times X_{t 1}$

\section{Sistem Proteksi}

Sistem proteksi bertujuan mencegah kerusakan peralatan terhadap gangguan, sehingga penyaluran tenaga listrik dapat dipertahankan dan untuk melokalisir daerah gangguan menjadi sekecil mungkin. Salah satu alat pengaman yang digunakan adalah relay. Relay pengaman harus memenuhi persyaratan seperti keselektifan yang baik agar mencapai keandalan sistem yang tinggi karena tindakan pengaman yang cepat, tepat dan peka akan mengurangi gangguan menjadi sekecil mungkin [6].

\section{Setting Over Current Relay (OCR)}

Hasil perhitungan arus gangguan hubung singkat, pada tahap selanjutnya dipergunakan untuk menentukan setting over current relay, terutama nilai setting Time Multiple Setting (TMS) [5]. Untuk setting Over Current Relay (OCR) dihitung di incoming trafo, artinya [5] :

1. Untuk Over Current Relay (OCR) yang terpasang di penyulang dihitung berdasarkan arus beban maksimum yang mengalir di penyulang tersebut.

2. Untuk Over Current Relay (OCR) yang terpasang di incoming trafo dihitung berdasarkan arus nominal trafo.

Relay inverse biasa diset 1,05 - 1,1 x I beban, sedangkan difinite diset $1,2-1,3 \times$ I beban.

\section{E. Menghitung Setting Over Current Relay (OCR)}

Untuk menghitung setting arus lebih dapat dilakukan dengan cara berikut, Nilai setting relay penyulang $20 \mathrm{kV}$ [9] :

$$
I_{\text {set(primer })}=1,05 \times I_{\text {beban }}
$$

Keterangan :

$\mathrm{I}_{\text {set(primer) }}=$ Setting arus lebih karakteristik inverse

$\mathrm{I}_{\text {beban }} \quad=$ Arus beban maksimal penyulang

Nilai setting tersebut adalah nilai primer. Untuk mendapatkan setting sekunder yang dapat diset pada Over Current Relay (OCR), maka dihitung dengan menggunakan data ratio trafo arus yang terpasang di penyulang tersebut yaitu dengan rumus [5]:

$$
T=\frac{\beta \times T M S}{\left(\frac{I_{\text {fault }}}{I_{\text {set }}}\right)^{\alpha}-1}
$$

Keterangan :

$\mathrm{T}=$ Waktu trip (detik)

TMS = Time Multiple Setting

Ifault = Besarnya arus gangguan hubung singkat (Ampere) diambil arus hubung singkat terbesar

Iset $\quad=$ Besarnya arus setting sisi primer (Ampere) setting over current relay(inverse)

$\beta, \alpha=$ Konstanta ( faktor $\alpha$ dan $\beta$ tergantung pada kurva arus terhadap waktu)

Tabel 1. KONSTANTA A DANB

\begin{tabular}{|l|l|l|}
\hline Nama kurva & $\alpha$ & $\beta$ \\
\hline Standard Inverse & 0,02 & 0,14 \\
\hline
\end{tabular}

Untuk menentukan nilai TMS yang akan disetting pada Over Current Relay (OCR) adalah dengan rumus [9] :

$$
T M S=\frac{T \times\left(\left(\frac{I_{\text {fault }}}{I_{\text {set }}}\right)^{\alpha}-1\right)}{\beta}
$$

Keterangan :

TMS = Time Multiple Setting

$\mathrm{T}=$ Waktu Trip (detik)

Ifault = Besarnya arus gangguan hubung singkat (Ampere) diambil arus hubung singkat terbesar

Iset = Besarnya arus setting sisi primer (Ampere) setting over current relay(inverse)

$\beta, \alpha=$ Konstanta ( faktor $\alpha$ dan $\beta$ tergantung pada kurva arus terhadap waktu)

Untuk nilai setting incoming $20 \mathrm{kV}$ trafo tenaga, perlu dihitung terlebih dahulu arus nominal trafo tenaga yang sesuai dengan yang diketahui adalah kapasitas, tegangan, impedansi, ratio CT. Arus nominal trafo pada sisi $20 \mathrm{kV}$ dapat dicari dengan rumus [5]: 


$$
I_{\text {set }(\text { sekunder })}=I_{\text {set }(\text { primer })} \times \frac{1}{\text { Ratio } C T}
$$

Untuk setting waktu Time Multiple Setting (TMS), setting waktu relay standar Inverse dengan menggunakan rumus kurva waktu dan arus dalam hal ini juga diambil dari standar British, dengan rumus [5]:

$$
T=\frac{\beta \times T M S}{\left(\frac{I_{\text {fault }}}{I_{\text {set }}}\right)^{\alpha}-1}
$$

Untuk nilai TMS yang akan di setting pada relay arus lebih di sisi incoming $20 \mathrm{kV}$ dihitung dengan rumus yang sama :

$$
T M S=\frac{T \times\left(\left(\frac{I_{\text {fault }}}{I_{\text {set }}}\right)^{\alpha}-1\right)}{\beta}
$$

Nilai setting TMS yang didapat masih harus diuji dengan arus gangguan yang lain seperti arus gangguan hubung singkat untuk lokasi gangguan 3 fasa yang terjadi di lokasi gangguan. Demikian juga untuk jenis gangguan hubung singkat fasa ke fasa yang besar arus gangguannya juga sudah dihitung. Dengan cara yang sama dihitung nilai TMS pada Ground Fault Relay (GFR) berdasarkan hasil perhitungan arus gangguan satu fasa ke tanah, sehingga dengan demikian lengkap sudah setting relay yang diperlukan didalam sistem penyaluran distribusi yang dipasok dari trafo tenaga gardu induk [6].

\section{Metode PEnELITIAN}

Penelitian ini dilakukan dengan membuat simulasi arus gangguan hubung singkat dan membuat kurva koordinasi sistem proteksi menggunakan program ETAP. Data yang diperlukan pada penelitian ini adalah data jenis penghantar, panjang saluran penyulang Kedonganan, beban puncak dan data pengaman penyulang Kedonganan tahun 2016.

Proses perhitungan untuk mendapatkan nilai dari arus gangguan hubung singkat dan mendapatkan setting yang sesuai dengan syarat-syarat sistem pengaman dimulai dengan menghitung impedansi sumber, menghitung impedansi trafo, Setelah didapatkannya nilai impedansi jaringan, dilanjutkan dengan mensimulasikan arus hubung singkat antar 3 fasa, fasa ke fasa, dan arus hubung singkat 1 fasa ke tanah pada tiap-tiap zona lokasi gangguan dari hasil simulasi. Setting proteksi relay arus lebih kondisi eksisting dan hasil perhitungan sesuai data yang didapat. Penentuan nilai-nilai setting arus, setting waktu didasarkan pada syarat-syarat sistem pengamanan yang sensitif, handal, cepat dan selektif.

\section{HASIL DAN PEMBAHASAN}

\section{A. Perhitungan Impedansi}

Berdasarkan data nilai arus hubung singkat $\mathrm{I}_{\mathrm{hs}} 3 \emptyset \max$ pada sisi $150 \mathrm{kV}$ sebesar 12,059 kA sesuai dengan data trafo yang terpasang.

$$
\begin{aligned}
M V A_{h s} & =I_{h s} 3 \emptyset \max \times(\text { tegangan primer trafo } \times \sqrt{3}) \\
& =12,059 \mathrm{kA} \times(150 \mathrm{kV} \times \sqrt{3}) \\
& =3133 \mathrm{MVA}
\end{aligned}
$$

Berdasarkan hasil perhitungan diperoleh daya hubung singkat sumber sebesar 3133 MVA dan impedansi sumber disisi $20 \mathrm{kV}$ didapatkan sebesar $\mathrm{Z}_{(\text {sisi } 20 \mathrm{kV})}$ sebesar 0,128 Ohm.
Untuk perhitungan impedansi trafo. Trafo gardu induk Nusa Dua memiliki jenis belitan YNyn0 dan dengan daya nominal 60 MVA. Besarnya impedansi trafo di gardu induk Nusa Dua adalah 12,19\%. Setelah dilakukan perhitungan diperoleh nilai impedansi urutan positif dan negatif sebesar $0,81 \Omega$ dan impedansi urutan nol sebesar $8,1 \Omega$.

Perhitungan Impedansi Penyulang data yang diperoleh jenis penghantar yang digunakan pada penyulang Kedonganan menggunakan empat buah tipe kabel yaitu, AAAC $150 \mathrm{~mm}^{2}$, AAACS $150 \mathrm{~mm}^{2}$, MVTIC $150 \mathrm{~mm}^{2}$, XLPE $240 \mathrm{~mm}^{2}$.

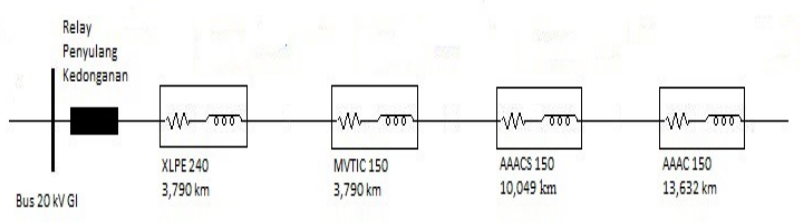

Gambar 1. Impedansi Jaringan Penyulang Kedonganan

Data perhitungan impedansi ini akan digunakan untuk simulasi arus gangguan hubung singkat.

B. Simulasi Arus Hubung Singkat

Simulasi perhitungan arus hubung singkat dilakukan di 5 lokasi eksisting yaitu pada bus203 terletak di kawasan kampus Teknik Universitas Udayana, Bus2 terletak di dekat LBS manual pole, bus128 terletak di jalan Poh Gading Jimbaran, bus 178 terletak di kawasan RSU pendidikan Unud dan bus 211 terletak di jalan kampus Auditorium Unud. Lokasi ini dipilih berdasarkan letak bus terdekat dari pangkal power grid sampai bus terjauh ujung power grid.

1. Simulasi hubung singkat pada lokasi alternatif 1 bus 203

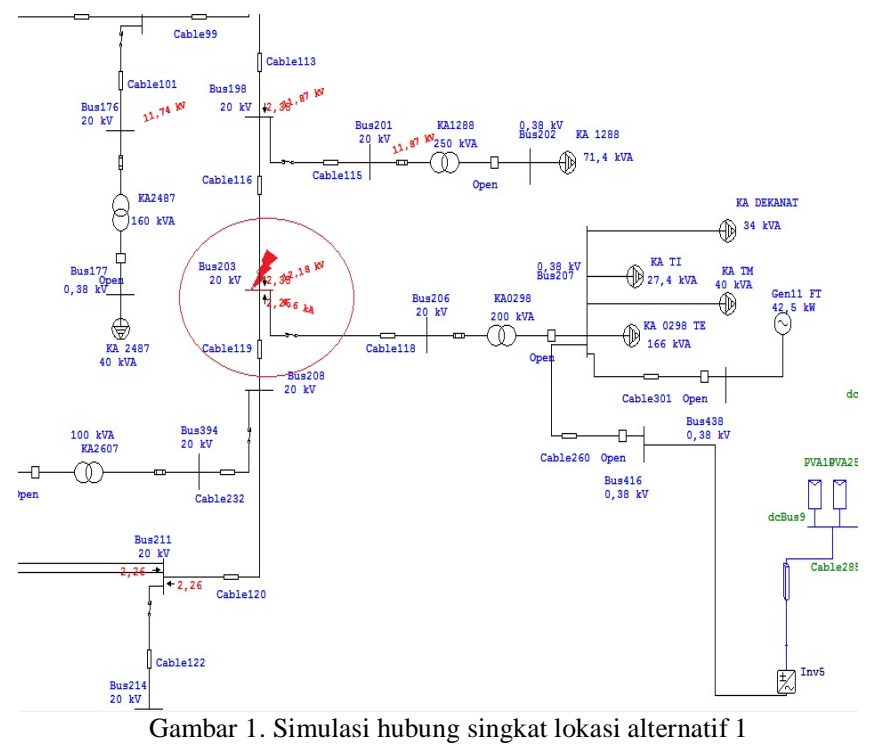

Simulasi perhitungan hubung singkat dilakukan pada lokasi alternatif 1 yaitu pada bus 203. Dimana pada lokasi alternatif 1 terdapat generator set dan PLTS sebagai backup jika terjadi pemadaman

Adanya gangguan hubung singkat yang terjadi pada lokasi alternatif 1 mengakibatkan perubahan aliran daya yang semula arus mengalir ke masing-masing bus berubah arah dan 
magnetudenya menuju ke bus yang terganggu. Hasil dari simulasi hubung singkat didapatkan sebagai berikut :

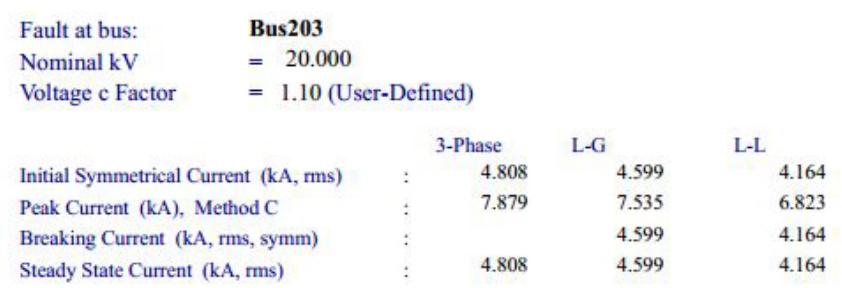

Gambar 2. Short circuit report lokasi alternatif 1

Dari hasil short circuit simulation arus hubung yang terjadi pada titik gangguan menyebabkan bus yang berada sebelum dan sesudah bus yang terganggu juga mendapatkan dampak dari gangguan tersebut.

2. Simulasi hubung singkat pada lokasi alternatif 2 bus 211

Simulasi perhitungan hubung singkat dilakukan pada lokasi alternatif2 yaitu pada bus211.

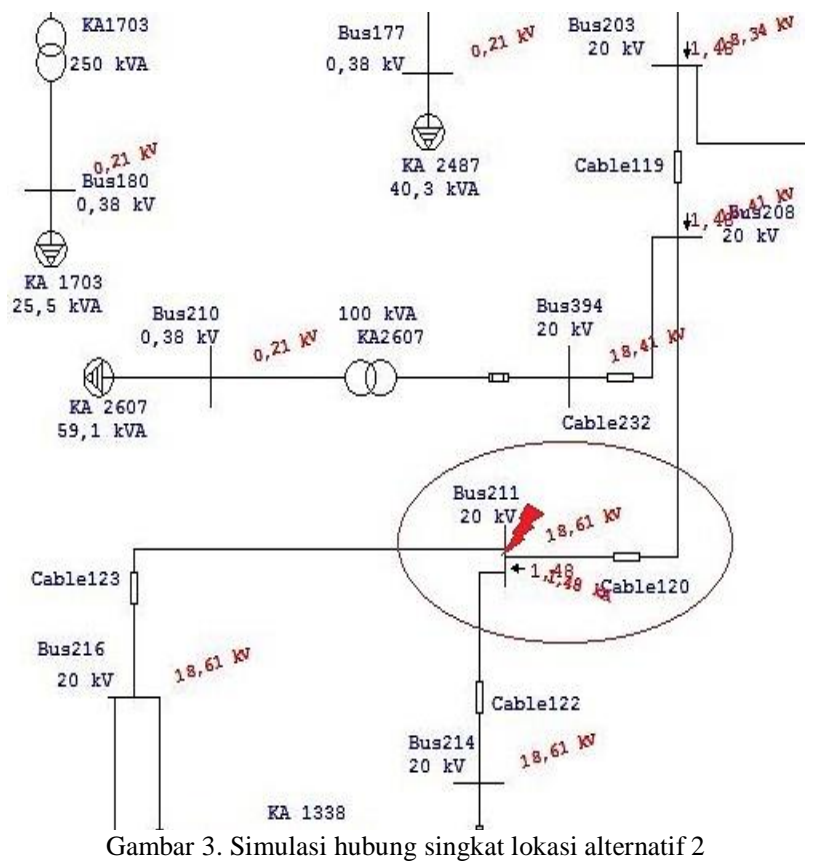

\begin{tabular}{|c|c|c|c|c|c|}
\hline Fault at bus: & \multicolumn{5}{|l|}{ Bus211 } \\
\hline Nominal $\mathrm{kV}$ & \multicolumn{5}{|l|}{$=20.000$} \\
\hline Voltage c Factor & \multicolumn{5}{|c|}{$=1.10$ (User-Defined $)$} \\
\hline & & & & L-G & L-L \\
\hline \multicolumn{2}{|c|}{ Initial Symmetrical Current ( $\mathrm{kA}, \mathrm{mms})$} & & 4.457 & 4.388 & 3.860 \\
\hline \multicolumn{2}{|c|}{ Peak Current (kA), Method C } & & 7.303 & 7.189 & 6.324 \\
\hline \multicolumn{2}{|c|}{ Breaking Current ( $\mathrm{kA}$, rms, symm) } & & & 4.388 & 3.860 \\
\hline \multicolumn{2}{|c|}{ Steady State Current (kA, rms) } & : & 4.457 & 4.388 & 3.860 \\
\hline
\end{tabular}

Gambar 4. Short circuit report lokasi alternatif 2

Short circuit report didapatkan nilai arus hubung singkat tiga fasa sebesar 4,457 kA, fasa ke fasa sebesar $3,860 \mathrm{kA}$, dan satu fasa ke tanah sebesar 4,388 kA.

3. Simulasi hubung singkat pada lokasi alternatif 3 bus 178

Perhitungan hubung singkat dilakukan pada lokasi alternatif 3 yaitu pada bus 178 .

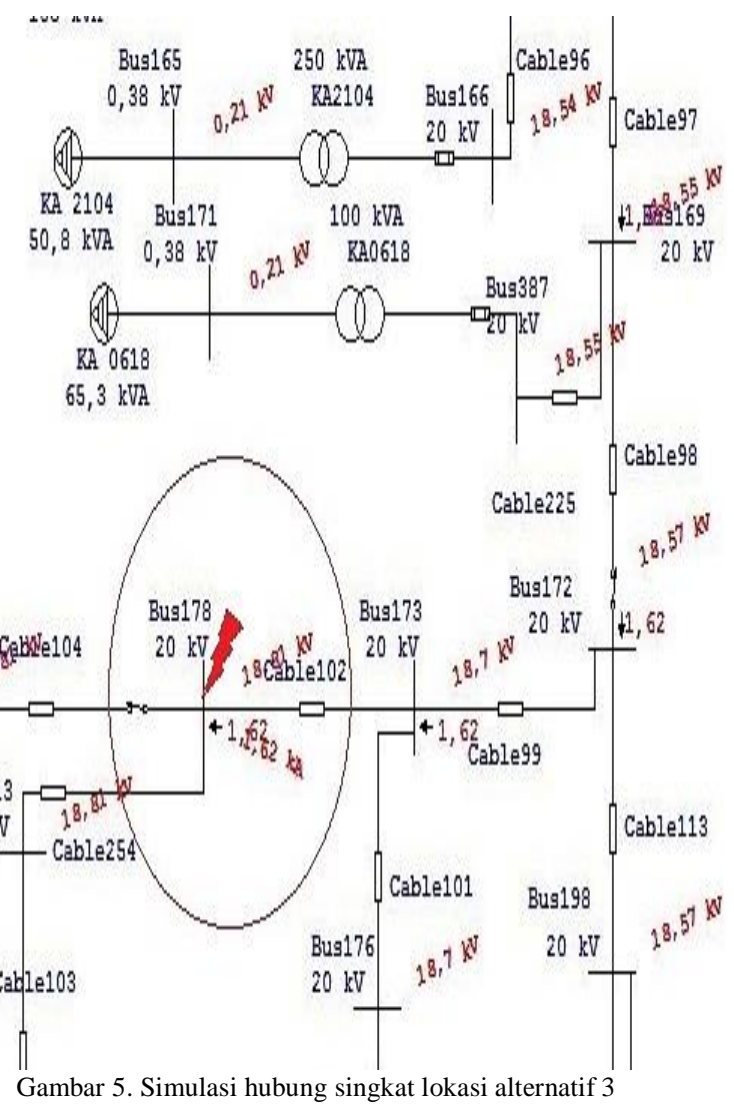

$\begin{array}{ll}\text { Fault at bus: } & \text { Bus178 } \\ \text { Nominal kV } & =20.000 \\ \text { Voltage c Factor } & =1.10 \text { (User-Defined) }\end{array}$

\begin{tabular}{|c|c|c|c|c|}
\hline & & aase & L-G & L-L \\
\hline Initial Symmetrical Current (kA, rms) & : & 5.071 & 4.468 & 4.391 \\
\hline Peak Current (kA), Method C & : & 8.309 & 7.322 & 7.196 \\
\hline Breaking Current ( $\mathrm{kA}, \mathrm{rms}$, symm) & : & & 4.468 & 4.391 \\
\hline Steady State Current (kA, rms) & : & 5.071 & 4.468 & 4.391 \\
\hline
\end{tabular}

Gambar 6. Short circuit report lokasi alternatif 3

Short circuit report didapatkan nilai arus hubung singkat tiga fasa sebesar 5,071 kA, fasa ke fasa sebesar 4,391 kA, dan satu fasa ke tanah sebesar 4,468 kA.

4. Simulasi hubung singkat pada lokasi alternatif 4 bus2

Simulasi perhitungan hubung singkat dilakukan pada lokasi alternatif 4 yaitu pada bus 2 . 


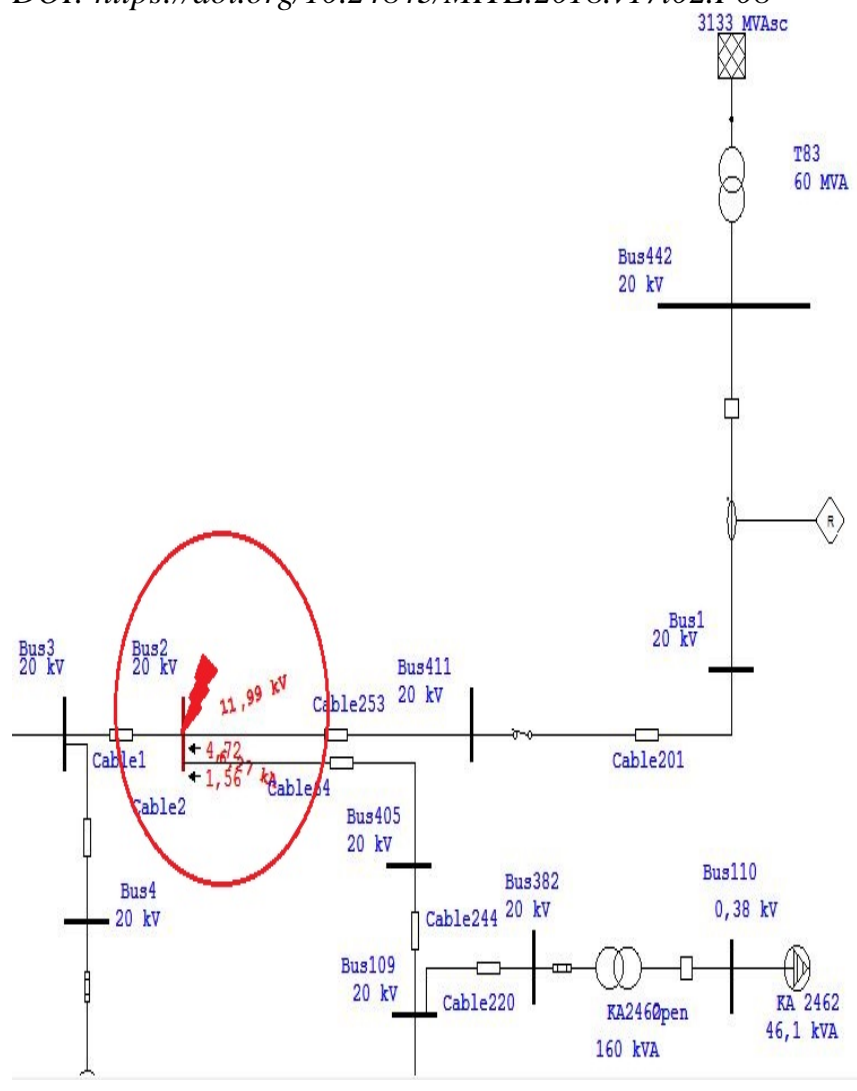

Gambar 7. Simulasi hubung singkat lokasi alternatif 4

$\begin{array}{lrrrr}\text { Fault at bus: } & \text { Bus2 } \\ \text { Nominal } \mathrm{kV} & =20.000 & & \\ \text { Voltage } \mathrm{c} \text { Factor } & =1.10 \text { (User-Defined) } & & \\ & & & \\ & \text { 3.Phase } & \text { L-G } & \text { L-L } \\ & 6.639 & 6.273 & 5.749 \\ \text { Initial Symmetrical Current (kA, rms) } & 10.897 & 10.297 & 9.437 \\ \text { Peak Current (kA), Method C } & & 6.273 & 5.749 \\ \text { Breaking Current (kA, rms, symm) } & 6.639 & 6.273 & 5.749 \\ \text { Steady State Current (kA, rms) } & & & \end{array}$

Gambar 8. Short circuit report lokasi alternatif 4

Short circuit report didapatkan nilai arus hubung singkat tiga fasa sebesar $6,639 \mathrm{kA}$, fasa ke fasa sebesar 5,749 kA, dan satu fasa ke tanah sebesar 6,273 kA.

Simulasi hubung singkat alternatif 4 pada bus2 mengalami gangguan tebesar. karena jarak gangguan hubung singkat yang terjadi pada bus2 dekat dengan Power Grid.

5. Simulasi hubung singkat pada lokasi alternatif 5 bus 128

Perhitungan hubung singkat dilakukan pada lokasi alternatif 5 yaitu pada bus128. Dapat dilihat hasil simulasi gangguan hubung singkat sebagai berikut,

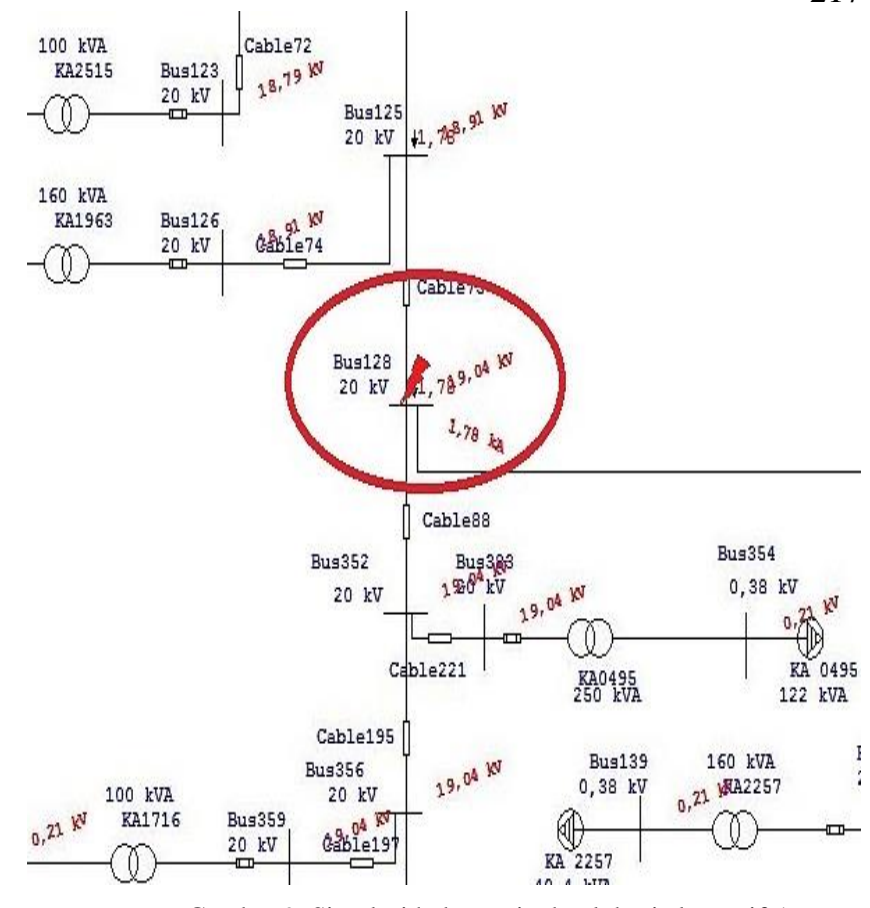

Gambar 9. Simulasi hubung singkat lokasi alternatif 5

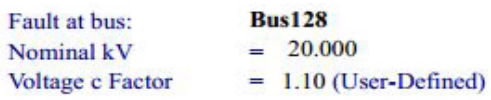

\begin{tabular}{llrrr} 
& & \multicolumn{2}{c}{ 3-Phase } & \multicolumn{2}{c}{ L-G } & \multicolumn{1}{c}{ L-L } \\
Initial Symmetrical Current (kA, rms) & $:$ & 5.899 & 5.497 & 5.109 \\
Peak Current (kA), Method C & $:$ & 9.668 & 9.010 & 8.373 \\
Breaking Current (kA, rms, symm) & $:$ & & 5.497 & 5.109 \\
Steady State Current (kA, rms) & $:$ & 5.899 & 5.497 & 5.109
\end{tabular}

Gambar 10. Short circuit report lokasi alternatif 5

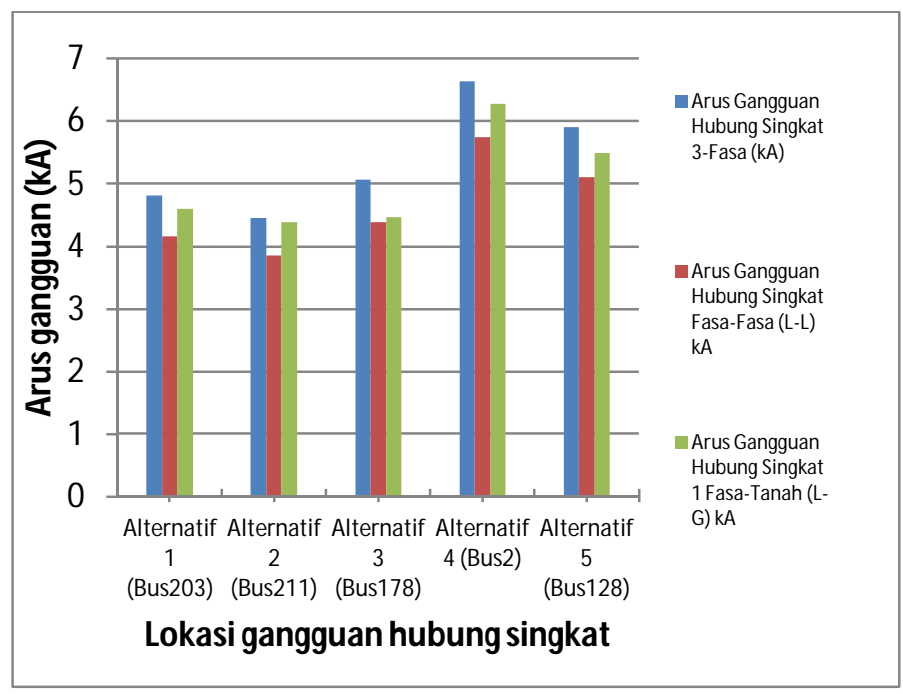

Gambar 11. Grafik hasil simulasi gangguan hubung singkat

Dilihat dari grafik hasil simulasi arus gangguan hubung singkat pada setiap lokasi gangguan yang dipilih secara acak, arus hubung singkat yang terkecil dihasilkan oleh bus211(bus yang terjauh dari power grid) sedangkan arus hubung singkat yang terbesar terjadi pada bus2(bus terdekat dengan power grid).

I Gde Km Jaryanta A.M: Analisa Hubung Singkat pada Jaringan .... 
Hasil ini sesuai dengan teori perhitungan hubung singkat yang menyatakan bahwa arus hubung singkat ditentukan oleh impedansinya. Semakin jauh bus gangguan dari power grid, maka impedansi salurannya akan semakin besar. Semakin besar impedansi maka arus hubung singkat akan semakin kecil. Sebaliknya semakin dekat bus gangguan dari power grid, maka impedansi saluran semakin kecil dan arus hubung singkat akan semakin besar [7].

\section{Perhitungan Setting Arus OCR dan GFR}

1. Setting arus over current relay penyulang kedonganan dan recloser camat kuta selatan menggunakan paduan karakteristik inverse time. Karakteristik inverse time diterapkan pada setting OCR pada recloser camat kuta selatan dan relay penyulang Kedonganan. Berdasarkan setting arus pada OCR dengan karakteristik inverse time dihitung menggunakan persamaan [5] sebagai berikut :

a. Setting OCR karakteristik inverse time relay penyulang Kedonganan

$$
\begin{aligned}
I_{\text {set }} & =1,05 \times I_{\text {beban penyulang }} \\
& =1,05 \times 300 \\
I_{\text {set }} & =315 \text { Ampere }
\end{aligned}
$$

b. Setting OCR karakteristik inverse time recloser camat kuta selatan

$$
\begin{aligned}
I_{\text {set }} & =1,05 \times I_{\text {beban rec }} \\
& =1,05 \times 250 \\
I_{\text {set }} & =265,5 \text { Ampere }
\end{aligned}
$$

2. Setting arus Ground fault relay (GFR) pada relay penyulang Kedonganan dan recloser camat kuta selatan menggunakan karakteristik inverse time. Setting arus GFR mengacu pada standar [5] dan dapat dihitung dengan menggunakan persamaan sebagai berikut:

a. $\quad$ Setting GFR relay penyulang Kedonganan

$$
\begin{aligned}
I_{\text {set GFR }} & =10 \% \times I_{\text {set }} \text { OCR } \\
& =10 \% \times 315 \\
I_{\text {set GFR }} & =31,5 \text { Ampere }
\end{aligned}
$$

b. Setting GFR recloser camat kuta selatan

$$
\begin{aligned}
I_{\text {set GFR }} & =10 \% \times I_{\text {set }} \text { OCR } \\
& =10 \% \times 265,5 \\
I_{\text {set GFR }} & =26,5 \text { Ampere }
\end{aligned}
$$

\section{Perhitungan Setting waktu OCR dan GFR}

Setting waktu pada OCR dan GFR dengan karakteristik inverse time menggunakkan time multiple setting (TMS). Setting TMS pada OCR pada recloser camat Kuta Selatan dan relay penyulang Kedonganan menggunakan nilai arus gangguan hubung singkat antar 3 fasa terbesar. Waktu kerja relay arus lebih pada nilai arus gangguan 3 fasa maksimum ditentukan selama 0,3 detik dengan karakteristik standard inverse. Hal ini bertujuan untuk menghindari efek arus inrush pada saat pengisian tegangan setelah terjadinya trip ataupun manual load shedding [6] .

Seting waktu untuk TMS pada GFR recloser camat Kuta

\begin{tabular}{|c|c|c|c|}
\hline \multicolumn{2}{|c|}{ SETTING } & $\begin{array}{c}\text { RELAY } \\
\text { PENYULANG }\end{array}$ & $\begin{array}{c}\text { RECLOSER } \\
\text { CAMAT KUTA }\end{array}$ \\
\hline \multirow{3}{*}{ OCR } & I set (A) & 315 & 265,5 \\
\hline & TMS & 0,314 & 0,14 \\
\hline & $\begin{array}{c}\text { Kurva } \\
\text { (Tanpa satuan) }\end{array}$ & SI & SI \\
\hline \multirow{3}{*}{ GFR } & I set (A) & 31,5 & 26,5 \\
\hline & TMS & 0,5 & 0,24 \\
\hline & Kurva & SI & SI \\
\hline
\end{tabular}
Selatan dan relay penyulang Kedonganan menggunakan nilai arus hubung singkat 1 fasa-tanah terbesar dengan karakteristik kurva standard inverse. Kurva karakteristik dari setting OCR dan GFR ditentukan berdasarkan granding time dan kecepatan waktu pemutus relay. Karakteristik kurva OCR dan GFR recloser camat Kuta Selatan dan relay penyulang Kedonganan ditentukan menggunakan standard inverse dengan granding time sebesar 0,4 detik bertujuan untuk meningkatkan selektifitas sistem pengaman [10].

Berdasarkan hasil perhitungan, diperoleh setting waktu seperti ditunjukkan pada tabel 2.

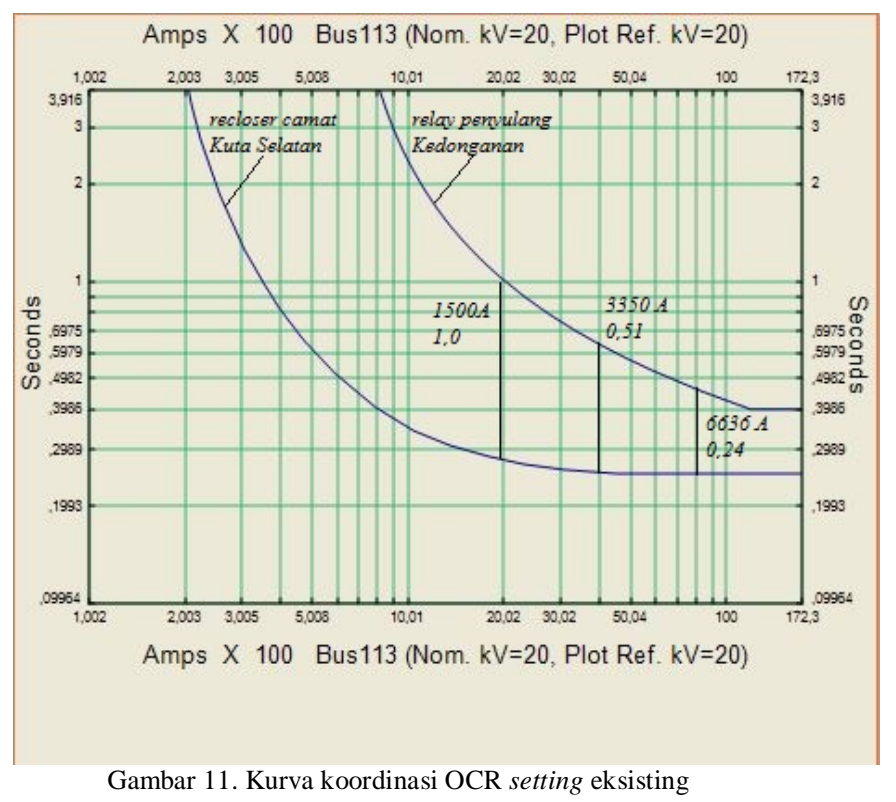

Berdasarkan kurva koordinasi OCR setting eksisting pada gambar 11, selektifitas sistem pengaman masih kurang baik. Grading time yang di dapat pada beberapa nilai arus hubung singkat masih berada 0,2 detik menunjukkan kurangnya selektifitas sistem pengaman.

\section{E. Analisis Kurva Koordinasi Proteksi OCR}

1. Analisis Kurva Koordinasi proteksi OCR Setting Eksisting

Berdasarkan data dari PT PLN Distribusi Bali, data kondisi eksisting OCR dan GFR relay penyulang Kedonganan dan recloser camat Kuta Selatan ditunjukkan pada tabel 3 .

Tabel 3. Setting OCR dan GFR kondisi eksisting hasil simulasi

\begin{tabular}{|c|c|c|}
\hline \multirow{2}{*}{ SETTING } & RELAY & RECLOSER CAMAT \\
& PENYULANG & KUTA SELATAN \\
& KEDONGANAN & \\
\hline
\end{tabular}




\begin{tabular}{|c|c|c|c|}
\hline \multirow{4}{*}{ OCR } & I set (A) & 300 & 250 \\
\cline { 2 - 4 } & $\begin{array}{c}\text { TMS } \\
\text { (tanpa satuan) }\end{array}$ & 0,175 & 0,1 \\
\cline { 2 - 4 } & Kurva & SI & SI \\
\hline \multirow{3}{*}{ GFR } & I set (A) & 48 & 30 \\
\cline { 2 - 4 } & TMS & 0,250 & 0,1 \\
\cline { 2 - 4 } & Kurva & SI & SI \\
\hline
\end{tabular}

Berdasarkan kurva koordinasi OCR setting eksisting pada gambar 11, selektifitas sistem pengaman masih kurang baik. Grading time yang di dapat pada beberapa nilai arus hubung singkat masih berada 0,2 detik menunjukkan kurangnya selektifitas sistem pengaman[10].

2. Analisis Kurva Koordinasi proteksi OCR dan GFR Setting Hasil Perhitungan

Perhitungan setting relay arus lebih OCR pada relay penyulang Kedonganan dilakukan untuk mendapatkan nilai setting yang baik dengan standar-standar sistem proteksi yang baik. Nilai setting yang baik akan menghasilkan koordinasi kerja yang optimal dan sesuai dengan syarat-syarat sistem proteksi.

Berdasarkan kurva koordinasi OCR setting hasil perhitungan pada gambar 12 sudah memenuhi syarat sistem penngaman yang baik. Granding time antar peralatan pengaman pada setiap tingkatan arus hubung singkat menunjukan nilai lebih dari 0,4 detik.

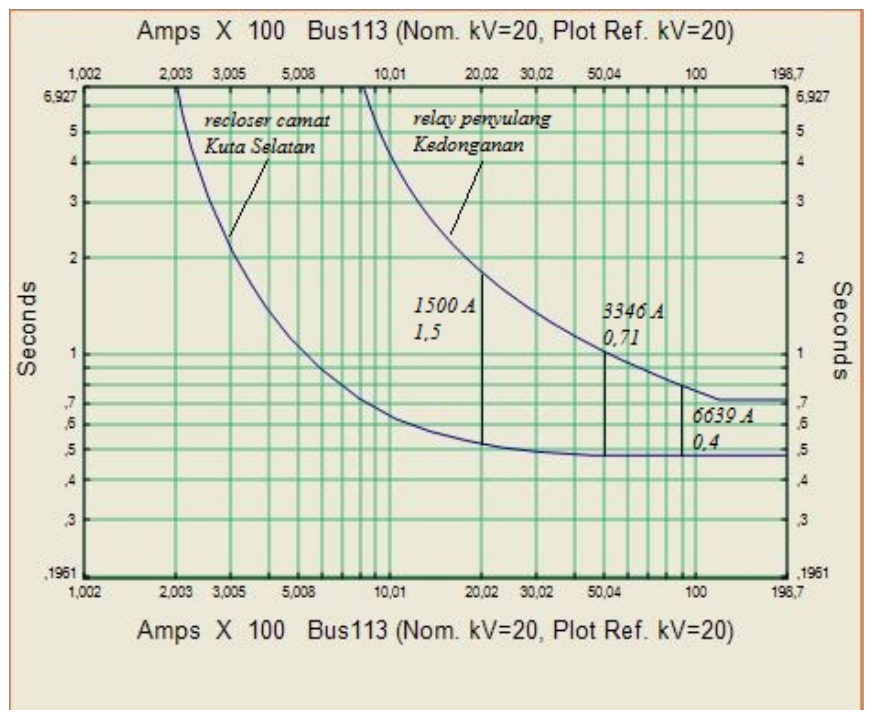

Gambar 12. Kurva koordinasi OCR setting hasil perhitungan

Granding time terlihat pada gambar kurva diatas, yang berada pada nilai 0,4 detik atau lebih akan memberikan kesempatan relay untuk memerintahkan circuit breaker (CB) bekerja, sehingga tidak menyebabkan peralatan pengaman utama bekerja terlebih dahulu (overlap) atau bekerja secara bersamaan. Koordinasi sistem pengaman yang memenuhi syarat selektif, cepat dan andal akan meminimalisir luasnya daerah pemadaman yang disebabkan oleh gangguan hubung singkat yang terjadi pada jaringan.

1. Penentuan setting arus, setting waktu dan pemilihan karakteristik kurva sangat berpengaruh terhadap,

a. Keandalan, bila terjadi ganguan maka relay harus bekerja dengan andal, relay tidak boleh gagal bekerja karena menyebabkan meluasnya pemadaman,

b. Kecepatan, waktu kerja relay cepat, makin cepat relay bekerja maka tidak hanya dapat memperkecil kerusakan akibat gangguan tetapi juga dapat memperkecil kemungkinan meluasnya gangguan. Jadi harus dapat memberikan selektivitas yang baik dengan waktu yang lebih cepat.

c. Selektifitas dan sensitifitas relay berpengaruh terhadap koordinasi peralatan proteksi gangguan hubung singkat agar relay dapat bekerja dengan baik.

2. Hasil setting relay arus lebih yang didapatkan dari simulasi ETAB, dapat disimpulkan bahwa setting OCR hasil simulasi penyulang Kedonganan lebih selektif dan baik. Direkomendasikan untuk dilakukannya setting ulang.

\section{REFERENSI}

[1] Chrisna Budi, Perencanaan Rekonfigurasi Jaringan Tegangan Menengah pada Kampus Universitas Udayana Bukit Jimbaran,"Majalah Ilmiah Teknik Elektro. Vol.15.No.1. Januari-Juni 2016.

[2] Gonen,T., Electric Power Distribution System Engineering. McGraw-Hill Education. 1998

[3] Grainger, J.J.,Stevenson, Jr.W.D. Analisis Sistem Tenaga terjemahan Ir.Kamal Idris, cetakan keempat,Jakarta : Erlangga. 1994

[4] Anderson, P.M, “Power System Protection" IEEE, PRESS, 1999

[5] British Standard. 142. Electrical protection relays. Spesification for thermal electrical relays.London :British Standard Institution. 1991

[6] IEEE Standards Association. 242.Recommended Practice for Protection and Coordination of Industrial and Commercil Power System. New York: The Institute of Electrical and Electronics Engineers, Inc. 2001

[7] Blackburn,J.L.,Domin,T.J. Protective Relaying Principle and Application.Third Edition London: Taylor \& Francis Group. 2006

[8] Kadarisman.P., Sarimun. W.N. Proteksi Sistem Distribusi Tegangan Menengah, Jakarta: PT. PLN (Persero). 2009.

[9] Indra Baskara, Studi Koordinasi Peralatan Proteksi OCR dan GFR pada Penyulang Tibubeneng, Majalah Ilmiah Teknologi Elektro, Vol.14 No.2, Juli-Desember 2015.

[10] S. Komari and W. Soekarto, "Kaidah Umum Penyetelan Rele.' PT. PLN Pusdiklat, 1995.

[11] I K Anom Astana Ady. 2016. Studi Pengaruh Setting Rele Pengaman Untuk Meminimalkan Gangguan Sympathetic Trip Pada Penyulang Bunisari - Suwung. "Majalah Ilmiah Teknik Elektro,Vol. 15. No.2,Juli-Desember 2016.

\section{KesimpUlan}

I Gde Km Jaryanta A.M: Analisa Hubung Singkat pada Jaringan .... 
[ Halaman ini sengaja di kosongkan] 